\title{
Article \\ Optimization of Lignin Extraction Variables by Response Surface Methodology from Pine Saw Dust, and Quantification of Major Structural Units in Isolated Lignin Fraction
}

\author{
Muhammad Ajaz Ahmed ${ }^{1}$, Jae Hoon Lee ${ }^{2}$ and Joon Weon Choi ${ }^{1, *}$ \\ 1 Institute of Green-Bio Science and Technology, Seoul National University, Pyeongchangdaero 1447, Korea; \\ m.ajaz@snu.ac.kr \\ 2 Department of Agriculture, Forestry and Bioresources, Seoul National University, Seoul 08826, Korea; \\ tirchonail@snu.ac.kr \\ * Correspondence: cjw@snu.ac.kr
}

Citation: Ahmed, M.A.; Lee, J.H.; Choi, J.W. Optimization of Lignin Extraction Variables by Response Surface Methodology from Pine Saw Dust, and Quantification of Major Structural Units in Isolated Lignin Fraction. Appl. Sci. 2021, 11, 1739. https://doi.org/10.3390/app11041739

Received: 13 January 2021

Accepted: 10 February 2021

Published: 16 February 2021

Publisher's Note: MDPI stays neutral with regard to jurisdictional claims in published maps and institutional affiliations.

Copyright: (c) 2021 by the authors. Licensee MDPI, Basel, Switzerland. This article is an open access article distributed under the terms and conditions of the Creative Commons Attribution (CC BY) license (https:/ / creativecommons.org/licenses/by/ $4.0 /)$.

\begin{abstract}
A synergistic combination of dioxane, acetic acid, and $\mathrm{HCl}$ was investigated for lignin extraction from pine wood biomass. After initial screening of reagent combination, response surface methodology (RSM) was used to optimize the lignin yield with respect to the variables of time 24-72 h, solids loading 5-15\%, and catalyst dose 5-15 mL. A quadratic model predicted $8.33 \%$ of the lignin yield, and it was further confirmed experimentally and through the analysis of variance (ANOVA). Lignin at optimum combination exhibited features in terms of derivatization followed by reductive cleavage (DFRC) with a value of $(305 \mu \mathrm{mol} / \mathrm{gm})$, average molecular weights of 4358 and polydispersity of 1.65 , and $2 \mathrm{D}$ heteronuclear single quantum coherence nuclear magnetic resonance spectrum (2D-HSQC NMR) analysis showing relative $\beta-\mathrm{O}-4$ linkages $(37.80 \%)$. From here it can be suggested that this fractionation can be one option for high quality lignin extraction from lignocellulosic biomass.
\end{abstract}

Keywords: pinewood; lignin extraction process; DFRC; 2D HSQC NMR

\section{Introduction}

Presently, the global community, with an aim to shape the future of bioeconomy, has put together rigorous efforts on the biorefining of biomass feedstocks [1]. These substrates, specifically the lignocelluloses due to their relative abundance and readily collectable nature, have become quite prominent candidates in this race [2]. However, their inclusive utilization still demands new technological processes to expand their boundaries for the production of sustainable products within the context of a biorefinery [3]. Among various lignocelluloses, pine wood biomass, a softwood, is an important feedstock with second highest contents (up to $30 \%$ on average) as lignin within their native biomass matrix [4].

This lignin, being an important macromolecule, is primarily composed of varying units of guaiacyl ( $\mathrm{G}$ units in pine wood biomass), syringyl (S units), and p-hydroxyphenyl ( $\mathrm{H}$ units) depending on the type of biomass species [5,6]. Lignin, with the presence of phenolic groups in its molecule, has become quite a versatile feedstock for the production of various sustainable materials [7]. These can be used for the production of rubbers, poly propylene, epoxy resins, and even carbon fibers [8-10]. Even more, this lignin can also be used as a partial substitute for the petroleum based resins minimizing thus the harmful impacts of toxic substances.

However, the lignin structure strongly varies with the adapted isolation process [11]. For example, lignin isolated via widely employed processes (such as Kraft, sulfite, organosolv, soda, etc.) differ widely not only among their molecular weights but also in their functional groups [11]. Although pulp and paper industry widely use the pulping processes (Kraft and sulfite) for lignin isolation, such kind of lignin offers less reactivity with 
high impurities and even so with severely modified structures making them less likely to be used for wider industrial applications [12,13].

Literally, there have been some good strategies to isolate the proto lignin including the famous milled wood lignin (MWL) and enzymatic lignin processes [14,15]. Similarly, the organosolv processes, taking advantage of organic acids, alcohols, or even from their synergistic effects, have also been found effective to extract the prototype lignin ensuring the solvent recovery as an additional benefit [16]. Recently gamma valerolactone (GVL) has been investigated as a potential reagent for the dissolution and extraction of lignin from lingocelluloses $[17,18]$. This organic solvent is a self-sustained product within a lignocellulosic biorefinery and is capable enough to extract lignin at near neutral solvent conditions [19].

Typically, GVL/acid/water has been mostly applied for an enhanced delignification rate with an improved cellulose digestion [20]. Being miscible with water, it induces better hydrolytic effects for biomass to dissolve out lignin [21]. It has also been applied under synergetic effects with metal salts, microwave, and with acids [22,23].

Additionally, there is a fair deal of studies on the lignin isolation from biomass species using both the dioxane and acetic acid as it has been reported that the acidic conditions effectively break the most frequent arylalkyl ether bonds and lignin carbohydrate complex leading to the formation of low molecular weight lignin. However, increasing thermal and acidic severity can cause lignin condensation [24]. Acetsolv is another one such process in which xylan portion of the biomass is dissolved by breaking glycosidic bonds with the help of acetic acid and also this acid catalyzes the cleavage of $\beta-\mathrm{O}-4$ linkages to yield soluble low weight aromatics. However, more severe conditions of hydrogen ions not only increase the hydrolysis but also degrade the secondary sugars [25]. Although acetic acid has been envisaged as one promising lignin isolation reagent equally effective for both softwood and hardwood biomass species, nonetheless, softwoods due to their relatively high portion of lignin contents demand for more harsh conditions [26]. Generally it has been applied as an acetic acid-water system catalyzed by $\mathrm{HCl}$ around $100^{\circ} \mathrm{C}$ and $2 \mathrm{~h}$ of time [27]. However, under such conditions it has been previously found that the lignin, dissolved during such processes, can condense back during the cooling process [28].

Therefore, in this study, we tried several organosolv reagent combinations (GVL, dioxane, and acetic acid catalyzed by $\mathrm{HCl}$ ) under mild thermal conditions and sorted one on the basis of its capacity to retain high quality of lignin extraction and further undertook its optimization using design expert software and employing Box Bhenken Design. After the optimization the lignin fraction was obtained and qualitatively analyzed in terms of its functional groups, molecular weights, and structural features and compared with the milled wood lignin.

\section{Materials and Methods}

\subsection{Preparation of Biomass}

Pine saw dust was collected from Gangwon province South Korea and was used as a model substrate in the experimentation. It was air dried, ground to 60 mesh size, and finally methanol extracted. The chemical composition of this saw dust was determined according to two step acid hydrolysis of National Renewable Energy laboratory's (NREL) standard analytical procedure and with wise method [29,30]. For the elemental analysis, an elemental analyzer (CHNS 932, LECO Corp., USA) was used and the contents of C, $\mathrm{H}$, and $\mathrm{N}$ were measured, and $\mathrm{O}$ contents were calculated by subtracting $\mathrm{C}, \mathrm{H}$, and $\mathrm{N}$ contents from $100 \%$. The heating value was determined by using a calorimeter Parr 6400 Calorimeter (Parr, USA). This saw dust had almost 5.4\% moisture contents, $49.7 \%$ carbon, $5.3 \%$ hydrogen, $0.2 \%$ nitrogen, and $44.8 \%$ oxygen. Regarding its compositional analysis in terms of major units, it was $60.8 \%$ for holocellulose and $28 \%$ for lignin. There were also extractives as $8.7 \%, 0.4 \%$ ash, and $4 \%$ moisture. The higher heating value was determined to be $18.9 \mathrm{MJ} / \mathrm{kg}$. 


\subsection{Fractionation of the Biomass Via Acid Catalyzed Process}

Pine saw dust was subjected to lignin isolation experiments at various specified reagent combination along with $\mathrm{HCl}$. For all the fractionation experiments, specially designed lab scale stainless steel cylindrical reactors, with a total volume of $500 \mathrm{~mL}$, were used. A measured quantity of pine saw dust and dissolving reagents were loaded and the mixture was homogenized completely with glass stirrers. All the experiments were carried out at mild temperature of $70{ }^{\circ} \mathrm{C}$ and/or at room temperature [31,32].

\subsection{Lignin Isolation}

After being treated for the desired time, the biomass slurries were first subjected to filtration using a Buchner funnel attached with a vacuum assembly. The residue was shifted to $2 \mathrm{~L}$ of beakers and was diluted by adding deionized water to precipitate out the lignin. After this, it was subjected to centrifugation and finally freeze-dried and saved in the refrigerator for any further experiments.

\subsection{Design of Experiments and Statistical Analysis}

For the selection of the lignin isolation variables and their ranges, we first performed an initial screening with different reagent combinations (dioxane: acetic acid, GVL acetic: acid and GVL: dioxane all catalyzed by different $\mathrm{HCl}$ doses) under various temperatures and time intervals with $10 \%$ solids loading. These combinations then were performed and their lignin yield, $G$ units' values, and molecular weights were analyzed accordingly. Keeping in view the lignin quality with highest $G$ units, a combination of dioxane: acetic acid and $\mathrm{HCl}$ was chosen. For the selection of the ranges of lignin isolation variables, we selected the center point values as $10 \%$ solids loading, $48 \mathrm{~h}$ of time, and $10 \mathrm{~mL}$ of catalyst dose based on our preliminary trials and their ranges were defined around this center point. These three factors (time, solids loading, catalyst dose), specific to the lignin isolation, play a fundamental role [33]. Solids loading is important in a sense that high solids loading is recommended for the desired economic operation of the biobased refineries [34]. The catalyst dose and time is also crucial as they play an important role of the catalyst mass transport into the biomass cell walls [35]. Talking specifically for the case of the lignin isolation, room temperature is important as it somehow mimics the classical proto lignin isolation process i.e., milled wood lignin [36].

After selecting these variables and their ranges, to further sort out the optimum experimental conditions, response surface methodology (RSM) was used with lignin yield as response $(\mathrm{Y})$. Three variables solids loading $\left(\mathrm{X}_{1}\right)$, catalyst dose $\left(\mathrm{X}_{2}\right)$, and time $\left(\mathrm{X}_{3}\right)$ were optimized and were tested in their ranges of $5-15 \%$ wt. for solids loading, $5-15 \mathrm{~mL}$ for $\mathrm{HCl}$ concentrations, and 24-72 $\mathrm{h}$ for time. Among from the experimental designs a Box-Behnken Design (BBD) with three center points was chosen to design the experiments. Data analysis was done with the help of Design Expert software (Version 8.0, State-Ease, Inc., USA). Lignin yield was calculated on the basis of initial weigh of lignin in pine saw dust.

\subsection{Structural Characterization of Isolated Lignin Samples (GPC, DFRC, 2DHSQCNMR)}

The recovered lignin fractions were analyzed by various qualitative analyses such as gel permeation chromatography (GPC), derivatization followed by reductive cleavage (DFRC), and 2D heteronuclear single quantum coherence nuclear magnetic resonance (HSQC NMR) spectrum by following the methods according to our previous studies [37]. Briefly, for GPC analysis, to determine the weight average (Mw) and number average $(\mathrm{Mn})$ molecular weights of the lignin samples, the isolated lignin fraction was firstly put to acetylation by dissolving it in a 1:1 ( $v: 0 \%)$ of pyridine and acetic anhydride solution. It was periodically shaken after every $30 \mathrm{~min}$ while maintaining a temperature of $105^{\circ} \mathrm{C}$ for almost $2 \mathrm{~h}$ in the oven. Afterwards, it was washed and freeze dried and $20 \mathrm{mg}$ of this acetylated lignin sample was dissolved in $2 \mathrm{~mL}$ of tetrahydrofuran (THF) followed by analyzing it on a GPC, Agilent 1200, USA (equipped with an ultraviolet detector (UV) on a PL-gel $5 \mathrm{~mm}$ Mixed-c. column. This was first calibrated with the standards of polystyrene 
and THF was run as the mobile phase at a flow rate of $1 \mathrm{~mL} / \mathrm{min}$. After running all the samples, the GPC chromatograms were also drawn. To this end, after doing the standards calibration, the graphs were drawn between the peak intensity and the time intervals. As a typical rule of size exclusion, the higher molecular weight curve is detected earlier followed by the successive less molecular weight curves. Similarly, in our case, MWL peak was shown earlier on GPC chromatogram having 10,660 molecular weight followed by DA lignin with 4718 molecular weight. Lastly the ODA lignin peak was detected as having the lowest molecular weight (4358). For the DFRC analysis, $20 \mathrm{mg}$ of lignin was dissolved in $5 \mathrm{~mL}$ of $(\mathrm{AcOH}+\mathrm{AcBr}(4: 1))$ solution and kept at $50^{\circ} \mathrm{C}$ for $1 \mathrm{~h}$ with periodic shaking. Afterwards it was dried and the residue was mixed with $2 \mathrm{~mL}$ of dioxane/acetic acid/water (5:4:1, $v / v / v)$ solution followed by zinc dust $(50 \mathrm{mg})$ addition. After $1 \mathrm{~h}$, an internal standard tetracosane together with $20 \mathrm{~mL}$ of each of $\mathrm{CH}_{2} \mathrm{Cl}_{2}$ and saturated $\mathrm{NH}_{4} \mathrm{Cl}$ were added and the $\mathrm{pH}$ of this whole mixture was set to around 2 with $\mathrm{HCl}$ and the phases were separated precisely. The organic phase was dried again on rotary evaporator and then finally subjected to acetylation and were quantified by GC-MS (Agilent 7890B USA). For 2D-HSQC-NMR, the lignin samples were prepared using $20 \mathrm{mg}$ of lignin and dissolving it in $0.75 \mathrm{~mL}$ DMSO-D6 and then the analysis data was acquired with a Bruker AVANCE 600 spectrometer (Bruker, Germany).

\section{Results and Discussion}

\subsection{Initial Experiments to Define Lignin Isolation Variables and Further Optimization by RSM}

Initially to find out the experimental hotspot we performed some laboratory trials and tried different reagent combinations on the basis of previous literature survey. The list of the adapted reagent combinations of dioxane-acetic acid, GVL-acetic acid and GVL-dioxane catalyzed by $\mathrm{HCl}$ along with their operating conditions are mentioned in Table 1 . As it can be seen in the table, the values in terms of lignin yield were quite noticeable for all the combinations with the highest value of $42 \%$ for GVL: acetic acid combination and the lowest one $2.5 \%$ with dioxane acetic acid conditions. These values are quite comparable with the previously published literature. For example, in a previous study, a lignin yield of $43 \%$ was obtained when organosolv reagent (H2O: EtOH/35:65 v/v) combination was employed at $162{ }^{\circ} \mathrm{C}$ for $78 \mathrm{~min}$ and with $1.6 \% \mathrm{H}_{2} \mathrm{SO}_{4}$ [38]. In a similar other study, a lignin yield of $23.8 \%$ was obtained from corn stover when deep eutectic solvent (choline chloride and formic acid (1:2)) were employed at a higher temperature of $130{ }^{\circ} \mathrm{C}$ for $2 \mathrm{~h}$ of time [39]. In our reagent combination of dioxane and acetic acid with $10 \mathrm{~mL}$ of $\mathrm{HCl}$ dose and at $70{ }^{\circ} \mathrm{C}$ of temperature for $6 \mathrm{~h}$ of process time a lignin yield of $11 \%$ was obtained and in a previous study a slightly higher yield of $14 \%$ was obtained when flax fiber was subjected to a two-step lignin extraction process with the help of formic acid and hydrogen peroxide [40]. For our case of dioxane and acetic acid although the yield is much lower, this lower yield can be anticipated due to the rather less harsh thermal conditions and such low yields are possible as in one previous study a lignin yield of $5 \%$ was obtained when imidazolium ionic liquids were used to treat woody biomass around $100{ }^{\circ} \mathrm{C}$ temperature and long retention times from 8 to $24 \mathrm{~h}[41]$.

Table 1. Different reagent combinations for lignin yield, $G$ units, $M_{W}$ and polydispersity values.

\begin{tabular}{|c|c|c|c|c|c|c|c|}
\hline Reagent $(50 \% v / v)$ & Temperature $\left({ }^{\circ} \mathrm{C}\right)$ & Time (h) & Lignin Yield (\%) & G Units * & Mw & Mn & PDI * \\
\hline Di:AA ${ }^{1 *}$ & 70 & 6 & 11 & $200 \pm 20$ & 4732 & 2290 & 2.06 \\
\hline Di:AA $2 *$ & Room temp. & 48 & 2.5 & $332 \pm 30$ & 4718 & 2473 & 1.90 \\
\hline GVL:AA ${ }^{1 *}$ & 70 & 6 & 42 & $100 \pm 35$ & 3604 & 1851 & 1.94 \\
\hline GVL:Di $2 *$ & 70 & 6 & 38 & $110 \pm 40$ & 4562 & 2064 & 2.21 \\
\hline
\end{tabular}

Di: $\mathrm{AA}^{2 *}=$ dioxane acetic acid with $5 \mathrm{~mL} \mathrm{HCl}$; GVL: $\mathrm{AA}^{1 *}=\mathrm{GVL}$ acetic acid with $10 \mathrm{~mL} \mathrm{HCl}$; GVL: $\mathrm{Di}^{2 *}=\mathrm{GVL}$ dioxane with $10 \mathrm{~mL} \mathrm{HCl}$; $\mathrm{PDI}^{*}=\mathrm{Mw} / \mathrm{Mn} ; \mathrm{G}$ Units ${ }^{*}=\mu \mathrm{mol} / \mathrm{g}$.

Since our objective was to extract high quality lignin, all these extracted samples were further subjected to the DFRC analysis and their results were quite different within 
themselves. As can be seen in the table, the highest DFRC value was for dioxane: acetic acid combination when they were treated at room temperature for about $48 \mathrm{~h}$ with a value of 332 units. However, this value dropped significantly to 200 units when this combination was subjected to mild thermal severity $70^{\circ} \mathrm{C}$ for about $6 \mathrm{~h}$ of time. Although in this case the yield was enhanced greatly to $11 \%$, the DFRC value was dropped as well indicating that this combination did not preserve well the prototype structure of the isolated lignin. Moreover, the synergism of the gamma valerolactone (GVL) with both the acetic acid and dioxane also did not preserve well the higher DFRC values and these were 100 and 110, respectively, mainly due to the high thermal severity $\left(70{ }^{\circ} \mathrm{C}\right)$ and high $\mathrm{HCl}$ dose $(10 \mathrm{~mL})$. For these two combinations, we did not observe any lignin yield with either $5 \mathrm{~mL} \mathrm{HCl}$ or at room temperature. As far as the molecular weight and the polydispersity are concerned, these values were also in a narrow margin but the improved polydispersity (1.90) was achieved with the highest DFRC value. Therefore, keeping in view the high efficiency of the synergism of dioxane: acetic acid under $\mathrm{HCl}$ catalyzed conditions we chose this combination and named this initial lignin as dioxane: acetic acid lignin (DA lignin) to further optimize in terms of high yield and with high DFRC values. To this end, we chose Design Expert software to sort out the optimum combination via a statistical way using response surface methodology. We selected three variables: time from 24 to $72 \mathrm{~h}$, solids loading from $5 \%$ to $15 \%$, and $\mathrm{HCl}$ dose from 5 to $15 \mathrm{~mL}$. All these variables with their values along with their different experimental combinations were performed accordingly and the response was tabulated and reported in Table 2.

Table 2. Actual values of the experimental combinations.

\begin{tabular}{ccccc}
\hline Scheme $\mathbf{1}$ & $\begin{array}{c}\text { Time } \\
\left(\mathbf{X}_{\mathbf{1}}\right)\end{array}$ & $\begin{array}{c}\text { Solids Loading } \\
\left(\mathbf{X}_{\mathbf{2}}\right)\end{array}$ & $\begin{array}{c}\text { Catalyst Dose } \\
\left(\mathbf{X}_{\mathbf{3}}\right)\end{array}$ & Lignin Yield (\%) \\
\hline 1 & 24 & 10 & 15 & 4.0 \\
2 & 24 & 10 & 5 & 2.0 \\
3 & 24 & 15 & 10 & 3.1 \\
4 & 24 & 5 & 10 & 3.5 \\
5 & 48 & 10 & 10 & 8.1 \\
6 & 48 & 15 & 15 & 9.0 \\
7 & 48 & 15 & 5 & 6.0 \\
8 & 5 & 15 & 8.0 \\
9 & 48 & 5 & 5 & 5.0 \\
10 & 48 & 10 & 10 & 8.3 \\
11 & 48 & 10 & 10 & 8.6 \\
13 & 48 & 15 & 10 & 10.0 \\
14 & 72 & 10 & 5 & 5.5 \\
\end{tabular}

For these performed experiments, the equation representing the adjusted quadratic model (model fitness with its significance suggested by software) in terms of coded factors is described in the following equation.

$Y=+8.33+2.742 X_{1}+0.45 X_{2}+1.69 X_{3}+0.60 X_{1} X_{2}+0.88 X_{1} X_{3}+0.000 X_{2} X_{3}-1.78 X_{1}^{2}-0.40 X_{2}^{2}-0.93 X_{3}^{2}$

where the lignin yield is denoted by $\mathrm{Y}$ and the isolation variables are represented as $\mathrm{X}_{1}$ time, $X_{2}$ as solids loading, and $X_{3}$ as catalyst dose. In order to study the model adequacy, the ANOVA table is presented in Table 3. For this model the adjusted R-squared value and R-squared values were 0.9857 and 0.9994 , respectively.

As it can be seen in the Table 2, the lignin yield varied quite considerably with the variation of the extraction conditions. It became fairly prominent with the catalyst dose and the time of the extraction process adapted. This evidence was also found from the ANOVA table. It is evidenced there that the model is quite significant having a $p$ value less than 0.0001 . Moreover, the adjusted $\mathrm{R}$ squared value as well as the $\mathrm{R}$ squared value 0.9857 and 0.9994, respectively, are noticeably high showing thus the model adequacy. In our model, the independent variables of both the time and catalyst dose have a quite significant 
impact on the lignin yield. For the time the $p$ value is $<0.0001$ showing a prominent effect on the yield. This phenomenon is mainly regarded as time prolongation that can help to loosen the native biomass web to dissolve out the lignin portion of the biomass under such conditions [42]. In the case of the catalyst dose, the $p$ value also exhibited a value lower than 0.0001 . This prominent effect is highly likely due to the strong protonation effect of the catalyst $\mathrm{HCl}$ [40]. This acid catalyst, regarding lignin isolation, offers a better selective extraction retaining a good quality [43].

Table 3. ANOVA for response surface optimization of the variables.

\begin{tabular}{|c|c|c|c|c|c|c|}
\hline Scheme 2 & Sum of Squares & df & Mean Square & F Value & $p$ Value Prob $>$ F & \\
\hline Model & 103.04 & 9 & 11.45 & 108.18 & $<0.0001$ & Significant \\
\hline $\mathrm{X}_{1}$-Time & 59.95 & 1 & 59.95 & 566.47 & $<0.0001$ & Significant \\
\hline $\mathrm{X}_{2}$-Solid loading & 1.62 & 1 & 1.62 & 15.31 & 0.0113 & \\
\hline $\mathrm{X}_{3}-$ Catalyst & 22.78 & 1 & 22.78 & 215.26 & $<0.0001$ & Significant \\
\hline $\mathrm{X}_{1} \mathrm{X}_{2}$ & 1.44 & 4 & 1.44 & 13.61 & 0.0142 & \\
\hline$x_{1} x_{3}$ & 3.06 & 1 & 3.06 & 28.94 & 0.0030 & \\
\hline$X_{2} X_{3}$ & 0.000 & 1 & 0.000 & 0.000 & 1.0000 & \\
\hline $\mathrm{X}^{2}{ }_{1}$ & 11.69 & 1 & 11.69 & 110.44 & 0.0001 & \\
\hline $\mathrm{X}^{2}{ }_{2}$ & 0.60 & 1 & 0.60 & 5.70 & 0.0626 & \\
\hline $\mathrm{X}^{2}{ }_{3}$ & 3.19 & 1 & 3.19 & 30.12 & 0.0027 & \\
\hline Residual & 0.53 & 5 & 0.11 & & & \\
\hline Lack of fit & 0.40 & 3 & 0.13 & 2.12 & & Not significant \\
\hline Pure error & 0.13 & 2 & 0.063 & & & \\
\hline
\end{tabular}

However, in the case of solids loading it was not found to be that significant with a comparatively higher value of 0.0113 . For this variable, under our conditions it is anticipated that the catalyst was not penetrated enough to open up the recalcitrant structure to dissolve out the lignin portion. This interactive behavior is due to the fact that the higher biomass loading needed some additional thermomechanical and/or thermochemical treatments to expose the inner biomass surfaces for the catalyst transport as the outer biomass layer may swell, due to the acidic environment, on the surface offering a hindrance for the catalyst to penetrate deep inside [44].

For the interactive effects, it was found that only the effects of time and catalyst dose have $p$ values (0.0030) less than 0.005 . This interactive effect is quite obvious as both are significant even individually to cause the enhanced lignin yield. This similar trend was also obvious in our preliminary trials. Additionally, there are some previous studies where the similar trend was exhibited [45]. Therefore, it can be suggested that the synergism of both the time and $\mathrm{HCl}$ dose can lead to a better lignin yield but at room temperature. Regarding the interactive effects of time and solids loading, its $p$ value was 0.0142 showing not a significant effect and a similar trend was also observed in the case of the solids loading and the catalyst, where the $p$ value was also not significant and showed a value of 1.0000 .

Under all of the aforementioned conditions, the optimal lignin isolation combination was found out to be at $48 \mathrm{~h}$ of time, $10 \%$ of solids loading, with $10 \mathrm{~mL}$ of catalyst dose with a predicted lignin yield of $8.33 \%$. The predicted value was confirmed experimentally which yielded the lignin with $8.10 \%$. Our results are fairly comparative with previously published studies. For example, in one similar study, almost $15 \%$ lignin yield was obtained by adapting typical Soxhelet apparatus. In that study, they used dioxane with $0.4 \% v / v$ $\mathrm{HCl}$ and $3 \% v / v$ water for the extraction of low molecular weight lignin [46]. In another study, a lignin yield of $5 \%$ lower than our yield was obtained when imidazolium ionic liquids were used to treat woody biomass around $100{ }^{\circ} \mathrm{C}$ temperature and long retention times from 8 to $24 \mathrm{~h}$ [41]. In another study a lignin yield of $7.2 \%$ was obtained when sugar cane bagasse was dissolved in different concentrations of dioxane in $1 \% \mathrm{NaOH}$ to extract the lignin [47]. In one such study a lignin yield of Baruns's native lignin was almost $8 \%$ obtained from the woody biomass taking into account the proto lignin structure of the extracted lignin [48]. 


\subsection{Effect of Process Variables on the Lignin Yield}

In order to observe the experimental effects of all the three lignin isolation variables, $3 \mathrm{D}$ response surface graphs were also drawn (Figure 1). These plots exhibit the interaction of two variables while keeping the third at the center value. In Figure 1A, the effect of solids loading and time while keeping catalyst dose at a fixed value is shown. During the lignin isolation process, an elevated time and solids loading both led to a corresponding rise in the yield of lignin. However, after a certain time, a further increase of these variables resulted in less lignin yield. Moreover, in short time of the process no significant difference in the lignin yield was observed when then solids loading was varied $\mathrm{f}$ between their range of $5-15 \% w / w$. Similarly, for the other two variables, the trend kept its similar behavior trend (Figure 1B,C).

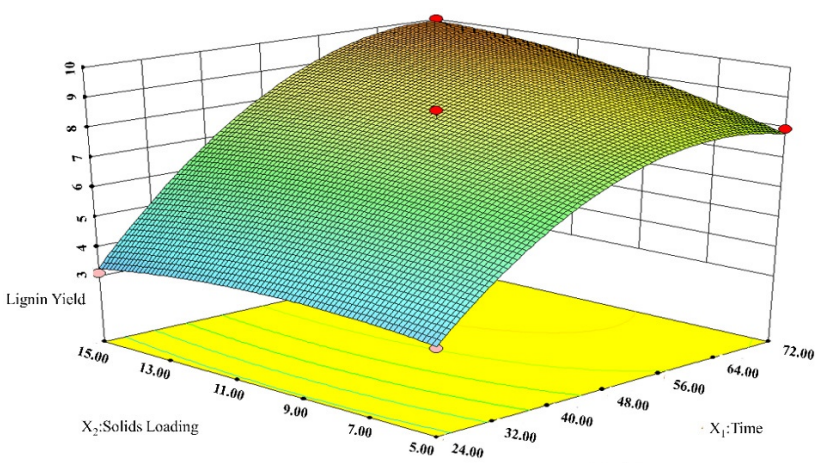

$\mathbf{A}$

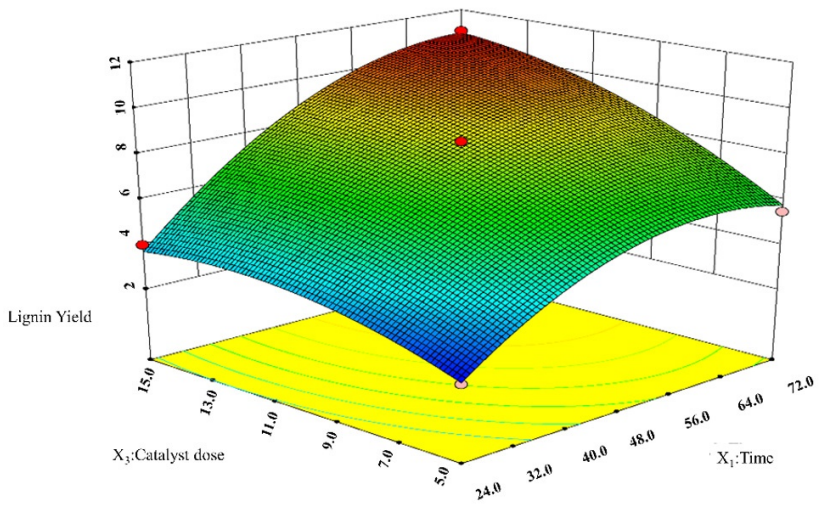

B

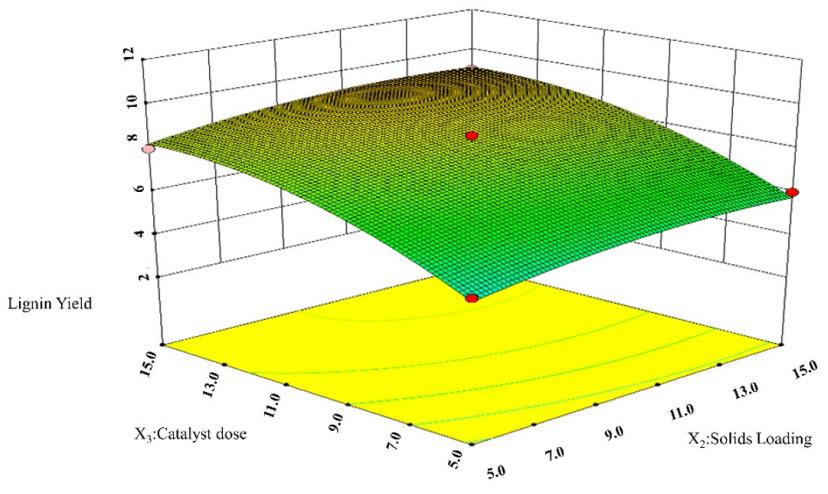

C

Figure 1. 3D response surface plots for interactive behaviour of process variables: (A) solids loading and time, (B) catalyst dose and time, and (C) catalyst dose and solids loading. 
As it is obvious from the figures, as solids loading and catalyst dose concentration rose, the yield concomitantly rose and then it decreased, indicating that neither harsh nor overly mild conditions had positive impacts on the lignin yield. However, the variables time and the catalyst strongly influenced the response (lignin yield) compared to the interaction of the process variables with solids loading, in our case only two process variables significantly contributed to the significance of quadratic model (value lower than $p=0.05$ ); from a point of view of the interactive effect of process variables, time and catalyst dose have had a significant role on the lignin yield and this similar trend was also observed in our preliminary trials. From here, it can be anticipated that under our prescribed range of factors time and catalyst dose played a significant role to have a substantial impact on the lignin yield.

\subsection{Molecular Weight Analysis of ODA and DA Lignin Samples}

In order to further determine the molecular weight of the lignin extracted at the optimum conditions, named as optimum dioxane acetic acid (ODA) lignin and the previously sorted DA lignin, the GPC analysis was also performed. For the reference, milled wood lignin was also analyzed and the results are reported in Table 4 . For the results of their molecular weights, the values are in comparison within each other but almost half of the milled wood lignin in terms of their weight average $\left(\mathrm{M}_{\mathrm{w}}\right)$ value. Regarding their polydispersity values it was improved from 1.90 for DA lignin to 1.65 for ODA lignin. This is also somewhat expected under our adapted conditions as the low catalyst dose released less amount of lignin to be released but a high dose also helped to increase the yield but also led to the formation of more lower molecular weight fractions and this was also evident from our model values. As it can be seen in the table, the molecular weight of ODA lignin was quite high with a value of 4358 and a corresponding polydispersity of 1.65 but as expected the values for DA lignin were 4718 and 1.90, respectively. As compared with the milled wood lignin, it has high value of polydispersity of 2.06 and the molecular weight was 10,660 units almost double the extracted lignin. These values are in a fair comparison with the previously published literature. For example, in one such previous study, a mixture of ethanol/water $(50 / 50 w / w)$ catalyzed by $1.2 \% w / w \mathrm{H}_{2} \mathrm{SO}_{4}$ was used at $180{ }^{\circ} \mathrm{C}$ and $1 \mathrm{~h}$ of time to isolate the lignin from eucalyptus showed a molecular weight value of 5079 but with a rather higher polydispersity of 3.24 [49]. In another study, the acetic acid (87\% aqueous $w / w)$ catalyzed by $\mathrm{HCl}(0.6 \mathrm{gm}$ of $36 \% w / w \mathrm{HCl}) 114{ }^{\circ} \mathrm{C}$ for $80 \mathrm{~min}$ was used to extract lignin from bamboo shoot shell and this lignin also exhibited a quite low molecular weight of 2789 with 1.54 of improved polydispersity quite closed to our ODA lignin value (1.65) [50]. Similarly, acetosolv lignin isolated from siam weed stem at $107^{\circ} \mathrm{C}$ for $3 \mathrm{~h}$ of time employing $93 \%$ acetic acid-water $v / v$ with $0.1 \%$ ( $w / w$ of liquid phase) $\mathrm{HCl}$ as catalyst showed a high polydispersity of 2.83 but with rather low molecular weight of 2010 [27].

Table 4. Molecular weights of Optimum Dioxane, Dioxane \& Milled Wood Lignin (ODA, DA, and MWL samples).

\begin{tabular}{cccc}
\hline Scheme 3 & $\mathbf{M}_{\mathbf{w}}$ & $\mathbf{M}_{\mathbf{n}}$ & $\left(\mathbf{M}_{\mathbf{w}} / \mathbf{M}_{\mathbf{n}}\right) \mathbf{P}$ \\
\hline MWL & 10,660 & 5157 & 2.06 \\
ODA lignin & 4358 & 2641 & 1.65 \\
DA lignin & 4718 & 2473 & 1.90 \\
\hline
\end{tabular}

For the GPC chromatograms, all of the three lignin samples exhibited the homogeneous curves showing their relative unique nature (Figure 2). In one of our previous studies, when the GVL was employed as a reagent for milled wood pine saw dust, the polydispersity was considerably high in the range of $2.54-2.96$ but under this process condition the polydispersity was noticeably improved [51]. From here it can be anticipated that the thermal conditions may lead to a harsher condition for the lignin isolation even under mild reagent conditions. 


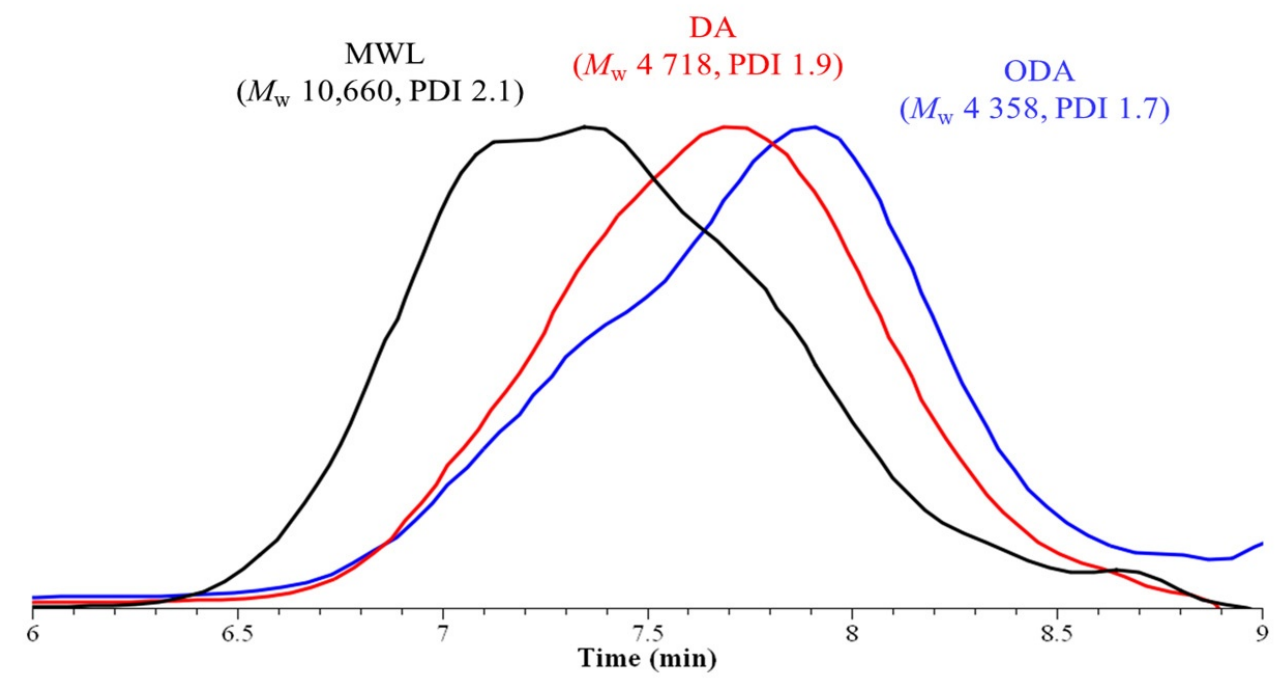

Figure 2. GPC chromatogram of ODA, DA, and MWL samples.

\subsection{DFRC Values of ODA and DA Lignin Samples}

To investigate further the lignin structure in terms of their typical qualitative units of both the lignin samples ODA and DA and to subsequently compare it with milled wood lignin a DFRC method was also used to degrade and finally isolate the $\beta$-aryl ether structures with the help of the reagents mentioned in the materials section. Finally, these fractions were studied by GC-MS and the results are shown in Table 5. As it is obvious in the table, both the lignin fractions show only $\mathrm{G}$ types of units due to a typical softwood biomass nature. The DFRC values for the milled wood lignin is around $450 \mu \mathrm{mol} / \mathrm{gm}$ and for the case of ODA lignin this value is somehow comparable with a value of 305 slightly lower than the DA lignin value of 332. It can be anticipated here that the ODA lignin was somewhat in lower value of DFRC than the DA lignin due to increased amount of $\mathrm{HCl}$ addition as it has also been previously reported [24]. Our values stand prominent with the previously investigated articles. One such study revealed that a lignin sample isolated from giant reed biomass had a $\mathrm{G}$ units' value of $285.7 \mu \mathrm{mol} / \mathrm{gm}$. This lignin was also isolated at rather mild conditions of $49^{\circ} \mathrm{C}$ for $24 \mathrm{~h}$ of time using $\mathrm{H}_{2} \mathrm{O}_{2}$ and $\mathrm{NaOH}$ as reagents [45]. Similarly, maize lignin also showed a G units' value of $342 \mu \mathrm{mol} / \mathrm{gm}$ while this lignin was isolated via the classical milled wood lignin method. In the similar study, the value was fairly increased to $504 \mu \mathrm{mol} / \mathrm{gm}$ when the bamboo lignin was isolated and characterized in the same way [52]. In one another study a value of these $G$ units of 310 was obtained when the Eucalypt globulus woody biomass was subjected to lignin isolation. In this study lignin was extracted via a classical pulping method with $\mathrm{Na}_{2} \mathrm{O}$ while keeping $30 \%$ sulfidity at a temperature of $80^{\circ} \mathrm{C}$ for about $120 \mathrm{~min}$ of time interval [53]. As it can be anticipated, the harsh lignin isolation conditions may lead to the cleaving of the aryl-ether linkages which are responsible for the higher DFRC values in the lignin samples [54].

Table 5. DFRC values of the ODA, DA, and MWL samples.

\begin{tabular}{cccc}
\hline Scheme & G Units & S Units & Total \\
\hline MWL & $450 \pm 34$ & - & $450 \pm 34$ \\
ODA lignin & $305 \pm 25$ & - & $305 \pm 25$ \\
DA lignin & $332 \pm 30$ & - & $332 \pm 30$ \\
\hline
\end{tabular}

Nonetheless, it can be suggested that our adapted process was quite meaningful in isolating the lignin with reasonable DFCR values proving thus that this modified process without thermal conditions has led to the less degradation of the lignin. 


\subsection{D HSQC NMR Spectra}

Finally, we also quantified the $\beta-\mathrm{O}-4$ contents present in the extracted lignin samples by performing their 2D-HSQC-NMR analysis. For this, $20 \mathrm{mg}$ of nonacetylated lignin was quantitatively used and was dissolved in $0.75 \mathrm{~mL}$ DMSO-D6 and then the analysis data was acquired with a Bruker AVANCE 600 spectrometer (Bruker, Germany). The relative quantification and the corresponding assignments of the $A_{\alpha}, B_{\alpha}$, and $C_{\alpha}$ are tabulated in Table 6 ( $\beta-\mathrm{O}-4, \beta-\beta$, and $\beta-5$, respectively) and the corresponding NMR figure is shown in Figure 3. The relative quantification of the present contents in the lignin samples were calculated accordingly. As can be seen in the table values. our extracted lignin, in comparison with MWL $(46.00 \%)$, was slightly lower in $\beta-\mathrm{O}-4$ contents ranging from $37.80 \%$ for ODA lignin to $40.00 \%$ for DA lignin. For the values of the other linkages in the lignin such as $\beta-\beta$ and $\beta-5$ a similar trend was observed but the value of $\beta-5$ (7.00 and 6.00 for ODA and DA, respectively) was closer to milled wood lignin value of 5.10. All these values were found to be in good comparison with the other process values. For example, in one of our previous studies this was around $28 \%$ for $\beta-\mathrm{O}-4$ contents when we adapted GVL as a sole reagent for the lignin isolation at a high temperature value ranging from 120 to $160^{\circ} \mathrm{C}$ without any acid dosing. This can be anticipated as the thermal conditions surely modify the lignin structure as well as the acid concentration. Although our values found in this study are slightly lower than the classical milled wood lignin value, they are still high enough to be compared with the previously published literature. For example, values of 33.0 and 19.3 of $\beta-\mathrm{O}-4$ linkages were reported when the baggase was treated with Ethanolamonium malonate $(2 \mathrm{He} \mathrm{Mal})$ and Ethanolamonium malonate (2He Lac), respectively. However, their lignin extraction conditions were still harsh with 150 and $160^{\circ} \mathrm{C}$, respectively [55]. In a similar other study, a value of 32.4 was obtained when the lignin was isolated from wheat straw with $62 \%(\mathrm{wt} \%)$ formic acid at $130{ }^{\circ} \mathrm{C}$ for $20 \mathrm{~min}$ of time [56]. However, in another study, a value of as high as $44.4 \beta-\mathrm{O}-4$ was reported when Eucalyptus camaldulensis Dehnh was treated with $80 \% \mathrm{GVL} / 20 \% \mathrm{H}_{2} \mathrm{O}$ mixture catalyzed by $20 \mathrm{~m} \mathrm{M} \mathrm{H}_{2} \mathrm{SO}_{4}$ for $30 \mathrm{~min}$ of time [57]. Almost similar values of $\beta-\mathrm{O}-4$ linkages were quantified as 45.54 units when abaca biomass was subjected to lignin isolation under alkaline conditions of $20 \mathrm{wt} \% \mathrm{NaOH}$ with $10 \mathrm{wt} . \% \mathrm{H}_{2} \mathrm{O}_{2}$ at a temperature of $105^{\circ} \mathrm{C}$ for a process time of $3 \mathrm{~h}$ [58].

Table 6. Relative amounts of linkages in lignin samples.

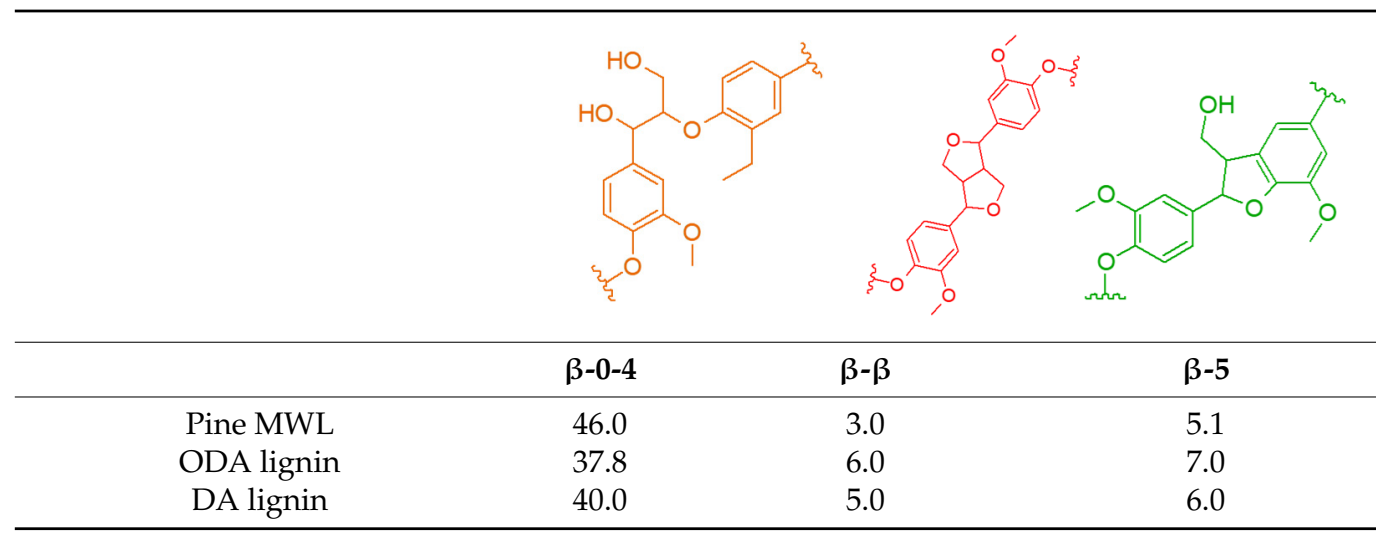



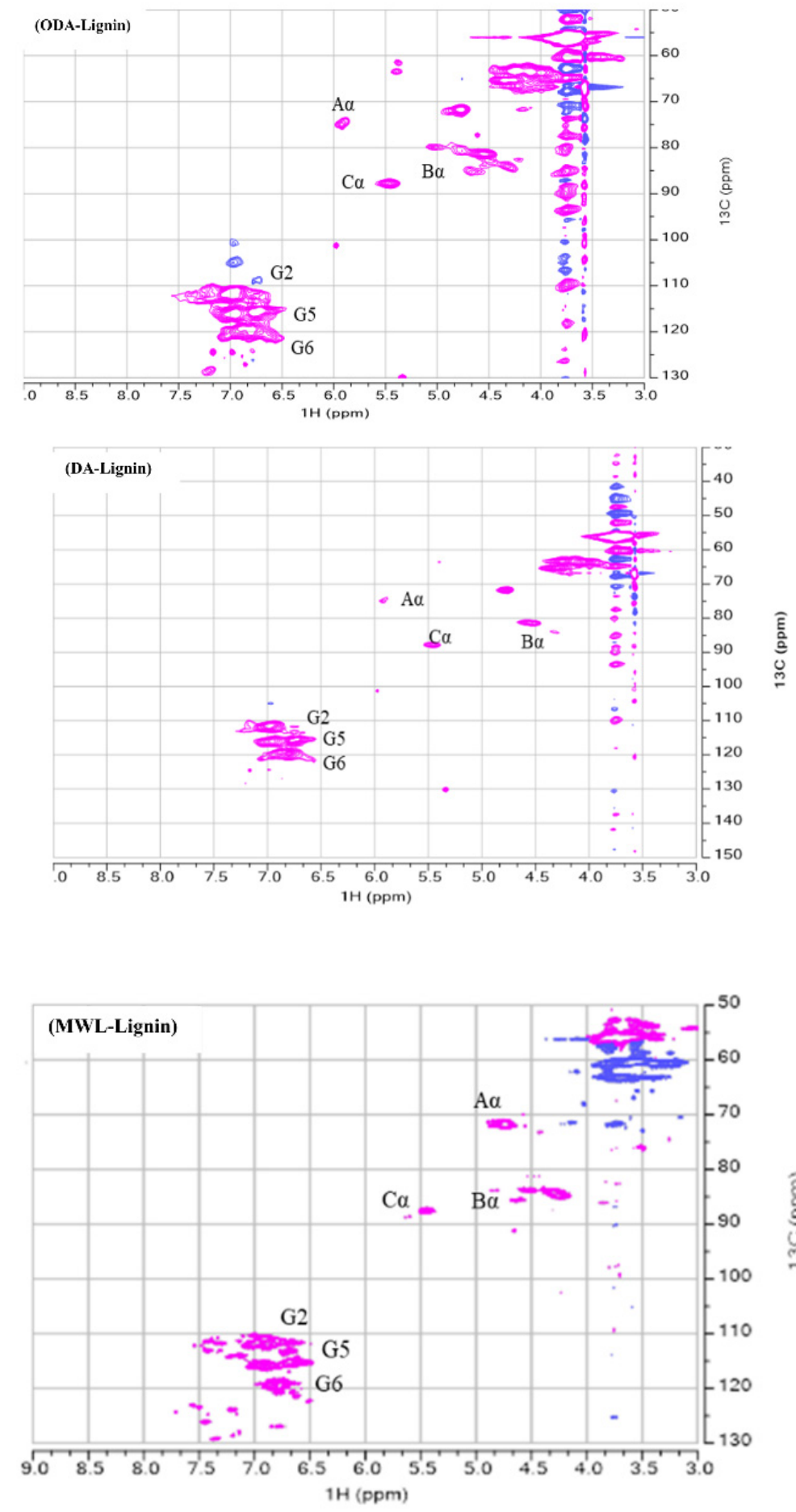

Figure 3. 2D HSQC NMR of ODA, DA, and MWL.

\section{Conclusions}

A new organosolv reagent combination was screened initially and statistically optimized subsequently to isolate high quality lignin fractions from pine saw dust at room temperature. Among from the three adapted process variables, only time and catalyst dose $(\mathrm{HCl})$ played a significant role on the response of lignin yield. At the optimal combination of $48 \mathrm{~h}$ of time, $10 \%$ solids loading, and $10 \mathrm{~mL} \mathrm{HCl}$ dose, a lignin yield as high as $8.10 \%$ was confirmed experimentally. A quadratic model fitness was suggested by the software to have a model significant value $<0.0001$ and with $R$-squared value of 0.9949 . This optimal lignin fraction (optimum dioxane-acetic acid ODA lignin) exhibited fairly higher $\mathrm{G}$ units' values 
(305 $\mu \mathrm{mol} / \mathrm{gm}$ ) together with the considerable $\beta-\mathrm{O}-4$ contents $(37.8 \%)$ worthy enough to be in comparison with the previously published studies. Moreover, this lignin fraction also showed a lower molecular weight with an improved polydispersity proving it to be a more uniform lignin fraction. This uniform molecular weight together with good proto lignin features make it a suitable candidate for diverse yet wider industrial applications including biocomposites, resins, and sustainable polymers. From this it can be conclusively suggested that this approach can be considered as one sustainable and green option for the fractionation of lignocelluloses specifically for the sole lignin extraction processes.

Author Contributions: Conceptualization, M.A.A.; Methodology, M.A.A.; Data curation M.A.A.; writing original draft, M.A.A.; Soft ware J.H.L.; Writing-review and editing, J.W.C.; Funding acquisition J.W.C.; All authors have read and agree to the published version of the manuscript.

Funding: This research was funded by the Basic Science Research Program (NRF-2019R1A2C2086328) and the Technology Development Program to Solve Climate Changes (2017M1A2A2087627) of the National Research Foundation funded by the Ministry of Science and ICT.

Institutional Review Board Statement: Not applicable.

Informed Consent Statement: Not applicable.

Data Availability Statement: The data sets are available within the manuscript.

Conflicts of Interest: The authors declare no conflict of interest.

\section{References}

1. Salvador, R.; Puglieri, F.N.; Halog, A.; de Andrade, F.G.; Piekarski, C.M.; De Francisco, A.C. Key aspects for designing business models for a circular bioeconomy. J. Clean. Prod. 2021, 278, 124341. [CrossRef]

2. Obydenkova, S.V.; Kouris, P.D.; Hensen, E.J.M.; Smeulders, D.M.J.; van der Meer, Y.; Boot, M.D. Industrial lignin from 2G biorefineries-Assessment of availability and pricing strategies. Bioresour. Technol. 2019, 291, 121805. [CrossRef] [PubMed]

3. Xu, H.; Kong, Y.; Peng, J.; Song, X.; Liu, Y.; Su, Z.; Li, B.; Gao, C.; Tian, W. Comprehensive analysis of important parameters of choline chloride-based deep eutectic solvent pretreatment of lignocellulosic biomass. Bioresour. Technol. 2021, $319,124209$. [CrossRef]

4. de França Serpa, J.; de Sousa Silva, J.; Borges Reis, C.L.; Micoli, L.; Alexandre e Silva, L.M.; Canuto, K.M.; Casimiro de Macedo, A.; Ponte Rocha, M.V. Extraction and characterization of lignins from cashew apple bagasse obtained by different treatments. Biomass Bioenergy 2020, 141, 105728. [CrossRef]

5. Yu, O.; Kim, K.H. Lignin to materials: A focused review on recent novel lignin applications. Appl. Sci. 2020, 10, 4626. [CrossRef]

6. Zhang, X.; Zhu, J.; Sun, L.; Yuan, Q.; Cheng, G.; Argyropoulos, D.S. Extraction and characterization of lignin from corncob residue after acid-catalyzed steam explosion pretreatment. Ind. Crops Prod. 2019, 133, 241-249. [CrossRef]

7. Vachon, J.; Assad-Alkhateb, D.; Baumberger, S.; van Haveren, J.; Gosselink, R.J.A.; Monedero, M.; Bermudez, J.M. Use of lignin as additive in polyethylene for food protection: Insect repelling effect of an ethyl acetate phenolic extract. Compos. Part C Open Access 2020, 2, 100044. [CrossRef]

8. Xu, L.; He, Z.; Zhang, H.; Wu, S.; Dong, C.; Fang, Z. Bioresource Technology Production of aromatic amines via catalytic co-pyrolysis of lignin and phenol-formaldehyde resins with ammonia over commercial HZSM-5 zeolites. Bioresour. Technol. 2021, 320, 124252. [CrossRef]

9. Le, N.D.; Trogen, M.; Ma, Y.; Varley, R.J.; Hummel, M.; Byrne, N. Cellulose-lignin composite fibers as precursors for carbon fibers: Part 2-The impact of precursor properties on carbon fibers. Carbohydr. Polym. 2020, 250, 116918. [CrossRef]

10. Younesi-Kordkheili, H.; Pizzi, A. Improving the properties of urea-lignin-glyoxal resin as a wood adhesive by small addition of epoxy. Int. J. Adhes. Adhes. 2020, 102, 102681. [CrossRef]

11. Bu, L.; Tang, Y.; Gao, Y.; Jian, H.; Jiang, J. Comparative characterization of milled wood lignin from furfural residues and corncob. Chem. Eng. J. 2011, 175, 176-184. [CrossRef]

12. Mazar, A.; Jemaa, N.; Wafa Al Dajani, W.; Marinova, M.; Perrier, M. Optimization of lignin recovery from the pre-hydrolysate of Kraft-Based dissolving pulp production processes. Appl. Sci. 2021, 11, 454. [CrossRef]

13. de Oliveira, D.R.; Avelino, F.; Mazzetto, S.E.; Lomonaco, D. Microwave-assisted selective acetylation of Kraft lignin: Acetic acid as a sustainable reactant for lignin valorization. Int. J. Biol. Macromol. 2020, 164, 1536-1544. [CrossRef]

14. Goundalkar, M.J.; Corbett, D.B.; Bujanovic, B.M. Comparative analysis of milled wood lignins (MWLs) isolated from sugar maple (SM) and hot-water extracted sugar maple (ESM). Energies 2014, 7, 1363-1375. [CrossRef]

15. Liu, X.; Li, T.; Wu, S.; Ma, H.; Yin, Y. Structural characterization and comparison of enzymatic and deep eutectic solvents isolated lignin from various green processes: Toward lignin valorization. Bioresour. Technol. 2020, 310, 123460. [CrossRef] 
16. Alvarez-Vasco, C.; Ma, R.; Quintero, M.; Guo, M.; Geleynse, S.; Ramasamy, K.K.; Wolcott, M.; Zhang, X. Unique low-molecularweight lignin with high purity extracted from wood by deep eutectic solvents (DES): A source of lignin for valorization. Green Chem. 2016, 18, 5133-5141. [CrossRef]

17. Ovejero-Pérez, A.; Rigual, V.; Domínguez, J.C.; Alonso, M.V.; Oliet, M.; Rodriguez, F. Acidic depolymerization vs ionic liquid solubilization in lignin extraction from eucalyptus wood using the protic ionic liquid 1-methylimidazolium chloride. Int. J. Biol. Macromol. 2020, 157, 461-469. [CrossRef]

18. Tan, X.; Zhang, Q.; Wang, W.; Zhuang, X.; Deng, Y.; Yuan, Z. Comparison study of organosolv pretreatment on hybrid pennisetum for enzymatic saccharification and lignin isolation. Fuel 2019, 249, 334-340. [CrossRef]

19. Ye, L.; Han, Y.; Feng, J.; Lu, X. A review about GVL production from lignocellulose: Focusing on the full components utilization. Ind. Crops Prod. 2020, 144, 112031. [CrossRef]

20. Sun, S.N.; Chen, X.; Tao, Y.H.; Cao, X.F.; Li, M.F.; Wen, J.L.; Nie, S.X.; Sun, R.C. Pretreatment of Eucalyptus urophylla in $\gamma$-valerolactone/dilute acid system for removal of non-cellulosic components and acceleration of enzymatic hydrolysis. Ind. Crops Prod. 2019, 132, 21-28. [CrossRef]

21. Jia, L.; Qin, Y.; Wen, P.; Zhang, T.; Zhang, J. Alkaline post-incubation improves cellulose hydrolysis after $\Gamma$-valerolactone/water pretreatment. Bioresour. Technol. 2019, 278, 440-443. [CrossRef]

22. Jin, L.; Yu, X.; Peng, C.; Guo, Y.; Zhang, L.; Xu, Q.; Zhao, Z.K.; Liu, Y.; Xie, H. Fast dissolution pretreatment of the corn stover in gamma-valerolactone promoted by ionic liquids: Selective delignification and enhanced enzymatic saccharification. Bioresour. Technol. 2018, 270, 537-544. [CrossRef]

23. Li, X.; Liu, Q.; Si, C.; Lu, L.; Luo, C.; Gu, X.; Liu, W.; Lu, X. Green and efficient production of furfural from corn cob over H-ZSM-5 using $\gamma$-valerolactone as solvent. Ind. Crops Prod. 2018, 120, 343-350. [CrossRef]

24. Monties, B. Preparation of dioxane lignin fractions by acidolysis. Methods Enzymol. 1988, 161, 31-35.

25. Guo, X.; Fu, Y.; Miao, F.; Yu, Q.; Liu, N.; Zhang, F. Efficient separation of functional xylooligosaccharide, cellulose and lignin from poplar via thermal acetic acid/sodium acetate hydrolysis and subsequent kraft pulping. Ind. Crops Prod. 2020, 153, 112575. [CrossRef]

26. Vázquez, G.; Antorrena, G.; González, J.; Freire, S.; López, S. Acetosolv pulping of pine wood. Kinetic modelling of lignin solubilization and condensation. Bioresour. Technol. 1997, 59, 121-127. [CrossRef]

27. Zhao, X.; Liu, D. Chemical and thermal characteristics of lignins isolated from Siam weed stem by acetic acid and formic acid delignification. Ind. Crops Prod. 2010, 32, 284-291. [CrossRef]

28. Mouthier, T.; Appeldoorn, M.M.; Pel, H.; Schols, H.A.; Gruppen, H.; Kabel, M.A. Corn stover lignin is modified differently by acetic acid compared to sulfuric acid. Ind. Crops Prod. 2018, 121, 160-168. [CrossRef]

29. Ely, R.E.; Moore, L.A. Yields of Holocellulose Prepared from Ruminant Feces by Acid Chlorite Treatment. J. Dairy Sci. 1955, 38, 1017-1022. [CrossRef]

30. Sluiter, A.; Hames, B.; Ruiz, R.; Scarlata, C.; Sluiter, J.; Templeton, D.; Nrel, D.C. Determination of structural carbohydrates and lignin in biomass determination of structural carbohydrates and lignin in biomass. Lab. Anal. Proced. 2008, 1617, 1-16.

31. Zijlstra, D.S.; De Santi, A.; Oldenburger, B.; De Vries, J.; Barta, K.; Deuss, P.J. Extraction of lignin with high $\beta-O-4$ content by mild ethanol extraction and its effect on the depolymerization yield. J. Vis. Exp. 2019, 2019, 1-12. [CrossRef]

32. Zijlstra, D.S.; Lahive, C.W.; Analbers, C.A.; Figueirêdo, M.B.; Wang, Z.; Lancefield, C.S.; Deuss, P.J. Mild organosolv lignin extraction with alcohols: The importance of benzylic alkoxylation. ACS Sustain. Chem. Eng. 2020, 8, 5119-5131. [CrossRef]

33. Bello, F.; Chimphango, A. Optimization of lignin extraction from alkaline treated mango seed husk by high shear homogenizationassisted organosolv process using response surface methodology. Int. J. Biol. Macromol. 2021, 167, 1379-1392. [CrossRef]

34. Cheng, Y.S.; Zheng, Y.; Yu, C.W.; Dooley, T.M.; Jenkins, B.M.; Vandergheynst, J.S. Evaluation of high solids alkaline pretreatment of rice straw. Appl. Biochem. Biotechnol. 2010, 162, 1768-1784. [CrossRef]

35. Duque, A.; Manzanares, P.; Ballesteros, I.; Negro, M.J.; Oliva, J.M.; Saez, F.; Ballesteros, M. Optimization of integrated alkalineextrusion pretreatment of barley straw for sugar production by enzymatic hydrolysis. Process Biochem. 2013, 48, 775-781. [CrossRef]

36. Rencoret, J.; Marques, G.; Gutiérrez, A.; Nieto, L.; Jiménez-Barbero, J.; Martínez, Á.T.; del Río, J.C. Isolation and structural characterization of the milled-wood lignin from Paulownia fortunei wood. Ind. Crops Prod. 2009, 30, 137-143. [CrossRef]

37. Kim, J.Y.; Park, S.Y.; Lee, J.H.; Choi, I.G.; Choi, J.W. Sequential solvent fractionation of lignin for selective production of monoaromatics by Ru catalyzed ethanolysis. RSC Adv. 2017, 7, 53117-53125. [CrossRef]

38. Brahim, M.; Boussetta, N.; Grimi, N.; Vorobiev, E.; Zieger-Devin, I.; Brosse, N. Pretreatment optimization from rapeseed straw and lignin characterization. Ind. Crops Prod. 2017, 95, 643-650. [CrossRef]

39. Chen, Z.; Ragauskas, A.; Wan, C. Lignin extraction and upgrading using deep eutectic solvents. Ind. Crops Prod. 2020, 147, 112241. [CrossRef]

40. Watkins, D.; Nuruddin, M.; Hosur, M.; Tcherbi-Narteh, A.; Jeelani, S. Extraction and characterization of lignin from different biomass resources. J. Mater. Res. Technol. 2015, 4, 26-32. [CrossRef]

41. Miao, J.; Yu, Y.; Jiang, Z.; Tang, L.; Zhang, L. Partial delignification of wood and membrane preparation using a quaternary ammonium ionic liquid. Sci. Rep. 2017, 7, 1-12. [CrossRef]

42. Sun, R.; Lawther, J.M.; Banks, W.B. Effects of Extraction Time and Different Alkalis on the Composition of Alkali-Soluble Wheat Straw Lignins. J. Agric. Food Chem. 1996, 44, 3965-3970. [CrossRef] 
43. Li, M.F.; Sun, S.N.; Xu, F.; Sun, R.C. Formic acid based organosolv pulping of bamboo (Phyllostachys acuta): Comparative characterization of the dissolved lignins with milled wood lignin. Chem. Eng. J. 2012, 179, 80-89. [CrossRef]

44. Zhang, S.; Keshwani, D.R.; Xu, Y.; Hanna, M.A. Alkali combined extrusion pretreatment of corn stover to enhance enzyme saccharification. Ind. Crops Prod. 2012, 37, 352-357. [CrossRef]

45. Savy, D.; Nebbioso, A.; Mazzei, P.; Drosos, M.; Piccolo, A. Molecular composition of water-soluble lignins separated from different non-food biomasses. Fuel Process. Technol. 2015, 131, 175-181. [CrossRef]

46. Saha, M.; Saynik, P.B.; Borah, A.; Malani, R.S.; Arya, P.; Shivangi; Moholkar, V.S. Dioxane-based extraction process for production of high quality lignin. Bioresour. Technol. Rep. 2019, 5, 206-211. [CrossRef]

47. Zhang, A.P.; Liu, C.F.; Sun, R.C.; Xie, J. Extraction, purification, and characterization of lignin fractions from sugarcane bagasse. BioResources 2013, 8, 1604-1614. [CrossRef]

48. Radotić, K.; Mićić, M. Methods for Extraction and Purification of Lignin and Cellulose from Plant Tissues. In Sample Preparation Techniques for Soil, Plant, and Animal Samples; Humana Press: New York, NY, USA, 2016; pp. 365-376.

49. Gordobil, O.; Moriana, R.; Zhang, L.; Labidi, J.; Sevastyanova, O. Assesment of technical lignins for uses in biofuels and biomaterials: Structure-related properties, proximate analysis and chemical modification. Ind. Crops Prod. 2016, 83, 155-165. [CrossRef]

50. Gong, W.; Xiang, Z.; Ye, F.; Zhao, G. Composition and structure of an antioxidant acetic acid lignin isolated from shoot shell of bamboo (Dendrocalamus Latiforus). Ind. Crops Prod. 2016, 91, 340-349. [CrossRef]

51. Ahmed, M.A.; Lee, J.H.; Raja, A.A.; Choi, J.W. Effects of gamma-valerolactone assisted fractionation of ball-milled pine wood on lignin extraction and its characterization aswell as its corresponding cellulose digestion. Appl. Sci. 2020, 10, 1599. [CrossRef]

52. Lu, F.; Ralph, J. Detection and determination of p-coumaroylated units in lignins. J. Agric. Food Chem. 1999, 47, 1988-1992. [CrossRef]

53. Guerra, A.; Elissetche, J.P.; Norambuena, M.; Freer, J.; Valenzuela, S.; Rodríguez, J.; Balocchi, C. Influence of lignin structural features on eucalyptus globulus kraft pulping. Ind. Eng. Chem. Res. 2008, 47, 8542-8549. [CrossRef]

54. Kim, J.Y.; Hwang, H.; Park, J.; Oh, S.; Choi, J.W. Predicting structural change of lignin macromolecules before and after heat treatment using the pyrolysis-GC/MS technique. J. Anal. Appl. Pyrolysis 2014, 110, 305-312. [CrossRef]

55. Pin, T.C.; Nascimento, V.M.; Costa, A.C.; Pu, Y.; Ragauskas, A.J.; Rabelo, S.C. Structural characterization of sugarcane lignins extracted from different protic ionic liquid pretreatments. Renew. Energy 2020, 161, 579-592. [CrossRef]

56. Tian, G.; Xu, J.; Fu, Y.; Guo, Y.; Wang, Z.; Li, Q. High $\beta-\mathrm{O}-4$ polymeric lignin and oligomeric phenols from flow-through fractionation of wheat straw using recyclable aqueous formic acid. Ind. Crops Prod. 2019, 131, 142-150. [CrossRef]

57. Li, Y.J.; Li, H.Y.; Cao, X.F.; Sun, S.N.; Sun, R.C. Understanding the Distribution and Structural Feature of Eucalyptus Lignin Isolated by $\gamma$-Valerolactone/Water/Acid System. ACS Sustain. Chem. Eng. 2018, 6, 12124-12131. [CrossRef]

58. Ma, C.Y.; Wang, H.M.; Wen, J.L.; Shi, Q.; Wang, S.F.; Yuan, T.Q.; Sun, R.C. Structural elucidation of lignin macromolecule from abaca during alkaline hydrogen peroxide delignification. Int. J. Biol. Macromol. 2020, 144, 596-602. [CrossRef] 